\title{
ДИАГНОСТИКА ПРОФЕССИОНАЛЬНОЙ ИДЕНТИЧНОСТИ: ВАЖНЫЙ АСПЕКТ КАЧЕСТВА В РАБОТЕ
}

\section{DIAGNOSTICS OF PROFESSIONAL IDENTITY: AN IMPORTANT ASPECT OF QUALITY IN WORK}

\section{Boudaoud Karim}

Summary: The challenge of professional identity in organizations undoubtedly places the human future at the center of the consequences of hypercompetitiveness. This is due to the fact that the pressure on the individual is increasing in organizations, but primarily because the generations entering the labor market are not ready to sacrifice their "I" on the altar of this hypercompetitiveness. ... At least not without reason or support. That is why, for the sake of understanding and explaining reality, we propose to focus on this study of identity building, examining it in an area subject to strong ethical, financial, social and human pressure and image - the banking sector. The manager and HR department will eventually find light in the field, the response to the observed behavior. That is why we decided to first reveal, not in an exhaustive way, but as clearly as possible, so rich is the literature on this subject, the concept of professional identity in its human structure, within its framework. work, then in interaction with the various vectors that carry it. A research survey in the form of a questionnaire will reveal the interaction of the company / individual in building this identity and identify the key points that contribute to improving the quality of a person's work.

Keywords: professional identity, organization, human construction, society, personality construction. $\prod_{1}$ анная статья является частью исследования под названием восприятие профессиональной идентичности психологов в Алжире и России.

Профессиональная идентичность начинается с собственной идентичности. Кроме того, опираясь на некоторые элементы гуманитарных наук, чтобы попытаться определить концепцию, видение раскрывается в нескольких цветах, позволяя приблизиться к процессу профессиональной идентичности.

В «Рассуждении о происхождении и основаниях неравенства среди людей» Жан-Жак Руссо (1775) предлагает вычесть из определения человека все, что касается его изменений, произведенных обществом: мысль, разум, страсти, поведение. То, что остается от человека после этого процесса, - это существо, которое можно улучшить, то есть существо, которое может подняться к мысли, к сознанию. Такое существо ничто, которое может стать бесконечностью вещей. Следовательно, чело-
Будауд Карим

Аспирант, Казанский федеральный университет, Казань K-Budaud@stud.kpfu.ru

Аннотация: Сомнение профессиональной идентичности в организациях, несомненно, ставит будущее человека в центр последствий гиперконкурентоспособности. Это связано с тем, что в организациях усиливается давление на отдельного человека, но прежде всего потому, что поколения, приходящие на рынок труда, не готовы пожертвовать своим «я» на алтаре этой гиперконкурентоспособности. Вот почему, ради понимания и объяснения реальности, мы предлагаем сосредоточиться на этом исследовании построения идентичности, исследуя его в области, подверженной сильному этическому, финансовому, социальному и человеческому имиджевому давлению - банковский сектор. Менеджер и отдел управления человеческими ресурсами в конечном итоге найдут свет в сфере деятельности, ответ на наблюдаемое поведение. Вот почему мы решили сначала раскрыть, не исчерпывающим образом, но как можно более четко, настолько богата литература по этому предмету, концепции профессиональной идентичности в ее человеческом построении, в ее рамках. работать, то во взаимодействии с различными векторами, которые ее несут. Исследовательский опрос в форме анкеты позволит выявить взаимодействие компании / отдельного лица при построении этой идентичности и определить ключевые моменты, способствующие повышению качества работы человека.

Ключевые слова: профессиональной идентичности, организации, человеческое строительство, общество, построение личности.

век не определен быть тем или иным, он свободен, он совершенен, потому что с самого начала он ни к чему не предназначен; он становится тем, чем он является, по мере развития его истории в случае его выбора.

Сартр (1946) рассмотрит этот тезис о существовании энциалистической философии: в человеке существование предшествует сущности. Он объясняет, что вещь есть то, чем она является, а не то, чем она не является. Человек, напротив, не то, что он есть (его профессия в данном случае не определяет его), и он то, чем он не является (он может заниматься другой профессией). Другими словами, человек может своим выбором создать то, что он есть (его существование предшествует его сущности), он свободен, поэтому несет ответственность за то, что он есть.

Но не только философы исследуют устройство человека и его будущее. Виникотт (1975) связывает телесную трансформацию с закреплением самого себя и под- 
черкивает, что построение идеала эго переживается во взаимоотношениях с другими и требует определенного нарциссического вложения субъекта, это в психоаналитическом подходе. Гоффман (1973), используя более интерактивный подход и используя театральную метафору, развивает идею о том, что социальная жизнь подобна сцене (региону, где происходит представление), с ее актерами, аудиторией и кулисами: пространство позволяя актерам опровергать впечатление, производимое в спектакле. Он называет фасадом различные элементы, с которыми актер может играть, такие как декор, а также личный фасад (отличительные знаки, статус, одежда, мимика, пол, жесты и т.д.). Актеры выходят на сцену, предлагая зрителям образ, который они создают. У них может быть несколько ролей, причем одна из них не более верна, чем у другой, и дистанцироваться от них, играя на дозе уважения к правилу, которое они считают необходимым, или адекватный. Таким образом, будущее личности разыгрывается на этой сцене постоянного театра жизни.

Исходя из философских теорий о природе человека, мы понимаем, что человек совершенен и свободен. Следовательно, человек может стать бесконечным множеством вещей, но своим выбором он несет ответственность за свое существование. На этом этапе размышлений мы можем сказать, что работа человека придает ему ценность. Следовательно, если человек придает такое значение работе при определении своего эго, то это потому, что работа дает ему признание. Человек более или менее чувствителен к признанию, которое он получает от общества, других или самого себя, и именно эта степень чувствительности определяет место, которое он отводит работе в определении это я. Но если индивидуум, следовательно, может по закону стать бесконечным множеством вещей, он фактически станет только одним. Его существование, его встречи, его опыт заставят его делать выбор, в частности, в отношении его профессиональной деятельности. Мы осознаем здесь сложность и решающий характер выбора, который предоставляется человеку, особенно в профессиональной области, которая нас здесь интересует. Это объясняет, почему его идентичность действительно является конструкцией. Но о какой личности мы говорим?

Латинская основа названия «идентичность» помогает уточнить его значение: корень слова

«Идентичность» - это «іdem», означающее «то же самое». Таким образом, мы можем определить идентичность как «то, чем одно отличает одно сообщество от другого или отдельного человека от другого». Различие, составляющее идентичность, всегда основано на том, что присуще существу и является исключительным».

Согласно Дубару, идентичность строится вокруг трех измерений: эго, нас и других, представленных на диаграмме ниже (2000).

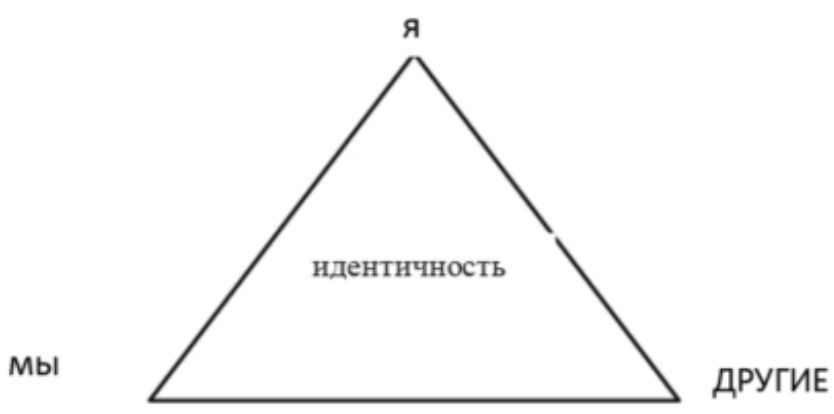

Рис. 1

Идентифицируемость и одновременно тождественность для себя и для других идентичности. Идентичность для себя, потому что она изначально относится к образу, который человек создает для себя. Идентичность для других - это также образ, который мы хотим отправить другим. Наконец, идентичность строится через образ, который нам присылают другие. Таким образом, идентичность - это результат процесса строительства. Это результат взаимодействия этих трех параметров. Исходя из этого определения идентичности, мы можем попытаться описать, что такое профессиональная идентичность, опираясь на различные положения.

Таким образом, профессиональная идентичность это прежде всего компонент общей идентичности человека, и она будет развиваться на основе личной идентичности путем регистрации человека в формах социальной жизни (Gohier, 2000). С глобальной точки зрения понятие профессиональной идентичности включает три основных элемента:

- жизненный мир труда: объективная рабочая ситуация и значение, придаваемое ей человеком,

- рабочие отношения: субъективное восприятие межличностных отношений и чувство принадлежности к неформальным группам,

- трахе ctoires профессиональное и восприятие будущего: описание различных этапов и изменения, связанные с бизнес - профессионала.

Профессиональная идентичность - это также то, как разные группы работников идентифицируют себя со сверстниками, лидерами и группой.

В более раннем исследовании отмечается, что 40\% опрошенных и 54\% работающих считают работу одним из элементов, которые лучше всего их определяют (Garnier, Meda, Senik, 2006). Таким образом, человек выбирает профессию в соответствии со своей личностью, стремлениями, способностями, опытом, а также своей чувствительностью к отрасли или конкретной деятельности. Выбор профессии является отражением лично- 
сти человека, каким он является во время этого выбора: «профессия мужчины является одним из важнейших компонентов его социальной идентичности. , его эго и даже его судьбы в его единственном существовании «

Теперь мы знаем различные элементы, которые формируют профессиональную идентичность человека. Нам остается пролить свет на различные особенности процесса построения идентичности. Процесс построения идентичности индивидуален в том смысле, что он является результатом личного выбора человека. Человек делает свои собственные выводы и уроки из своего опыта. Он присваивает жесты и правила своей профессии. Он наблюдает и индивидуализирует свои внешние переживания

Однако возможен ли этот индивидуальный процесс без социальных отношений и без коллективного равновесия? Этот вопрос заставляет нас думать, что идентичность индивида неизбежно включает определенные коллективные параметры. Как объяснялось ранее, человек строит свою личность на основе своего образования и начальной подготовки. Однако этой базы недостаточно. Создание идентичности требует обучения и ситуационной осведомленности. Именно в эти моменты возможны отношения с другими людьми, с компанией и с профессией. Без опыта других, без наблюдения, без обмена знаниями и советами построение идентичности сотрудников не то же самое. Коллективное измерение действительно облегчает и ускоряет этот процесс. Благодаря другим, человек может получить доступ ко всем существующим степеням признания. Здесь доказывается коллективное измерение процесса построения идентичности. Таким образом, построение идентичности хорошо построено как самим человеком, так и другими действующими лицами его профессиональной жизни.

Создание идентичности - это непрерывный, динамичный и интерактивный процесс. Другими словами, вторая характеристика процесса построения идентичности, разработанная здесь, состоит в том, что формирование профессиональной идентичности осуществляется на протяжении всей профессиональной жизни. Поэтому со временем он развивается. Он подвержен изменениям и развитию, навязанным компанией и ее экономической средой, а также самим человеком. Поэтому мы не можем говорить о профессиональной идентичности как о фиксированном или неизменном состоянии. Напротив, процесс устойчивый и непрерывно актуализируется взаимодействием различных факторов и индивидов. Идентичность адаптируется к контексту и опыту человека.

Сначала мы использовали философские теории, чтобы прийти к выводу, что человек совершенен и, следовательно, свободен выбирать, кем он будет в будущем, как в личном, так и в профессиональном плане. Мы пришли к выводу, что у человека нет предопределенной идентичности. Это строится на жизненном опыте. Впоследствии мы показали, что работа играет важную роль в самоопределении. Таким образом, если профессиональная деятельность человека является вектором идентичности, то это потому, что она дает ему признание в различных формах.

Затем мы проанализировали процесс создания идентичности на рабочем месте. Такой подход позволил нам определить исходные элементы профессиональной идентичности: образование, профессию, группы и компанию. В то же время мы характеризовали процесс построения идентичности как индивидуальный, так и коллективный, но, прежде всего, как непрерывный и нестабильный процесс.

Наконец, мы изучили контекст, в котором человек конструирует свою профессиональную идентичность. Мы понимали, что сотруднику нужен индивидуальный подход и особое внимание к его личным ожиданиям. Мы можем также признать, что в условиях нынешнего кризиса, сотрудник видит, что его место расстройства стратегических изменений, реализуемых компаниями. Действительно, кажется очевидным, что компания и ее сотрудники должны идти на компромиссы в этот опасный период. Таким образом, ситуация кажется неблагоприятной для построения идентичности. Таким образом, ставка для компании состоит в том, чтобы облегчить этот процесс, поскольку он напрямую связан с производительностью и вовлеченностью сотрудников.

\section{Методология}

Анкета, разосланная различным сотрудникам, была разработана по вопросам, касающимся профессиональной идентичности: чтобы побудить людей позиционировать себя по шкале предложений, мы решили отображать только закрытые вопросы в наших бланках. Этот выбор во многом оправдан, поскольку рассматриваемая здесь тема относительно деликатна. Фактически, этот метод позволяет преодолеть любое отвращение к высказыванию своего мнения о своей профессии, своей компании или степени удовлетворенности условиями работы или управления. Заметьте все же, что этот метод не оставляет места для развития идей и личного мнения. Анкета, рассылаемая различным сотрудникам, состоит из двух частей. Первый объединяет определенное количество вопросов, касающихся профессиональной идентичности, а второй позволяет собрать информацию о внутренних характеристиках человека. Это на пересечении этих двух типов по данные, что мы получим некоторые интересные выводы. Для этого были разработаны три типа вопросов: вопросы с несколькими предложениями, позиционирование от «полностью согласен» до 
«полностью не согласен» по предмету утверждения, классификация различных элементы ответа в порядке важности.

Наша сфера деятельности находится в банковском секторе, на уровне филиалов, в регионе BOUIRA ALGERIA, и ориентирована на респондентов, менеджеров по приему, консультантов по работе с клиентами, руководителей отделений. Для каждого опрошенного агентства у нас есть представители этих различных профессий, зная, что на директора агентства приходится от 3 до 15 менеджеров и советников, в зависимости от возраста. Из 43 человек, вовлеченных в эту работу (все сотрудники этих 6 агентств), 26 человек прислали нам свои ответы.

Наше исследование столкнулось с рядом ограничений. Они методологические и организационные.

Не все сотрудники, которым мы отправили копию анкеты, ответили. Однако мы зафиксировали более 50\% возвратов. В результате полученные ответы теоретически не отражают мнение сотрудников глобального банка и, следовательно, не претендуют на то, чтобы предлагать истины, которые можно обобщить на банковский сектор в целом.

Объект исследования сложен: несмотря на стремление упростить вопросы, мы понимаем, что некоторые элементы могут быть поняты по-разному в зависимости от опрошенных сотрудников.

Мы столкнулись с трудностями при заполнении окончательной анкеты. Некоторые сотрудники не хотели заполнять поля, отведенные для информации об их личности (пол, возраст и т.д.). Без сомнения, чтобы полностью защитить последнюю. Однако анкета была полностью анонимной и требовала только совокупной информации о человеке, полезной для нашего исследования. Таким образом, результаты были искажены из-за отсутствия информации, поэтому мы решили исключить эту часть исследования из нашей исследовательской работы. Поэтому мы не смогли перевести существующие корреляции между ответами сотрудников и их внутренними характеристиками или их профессиональными характеристиками (статусом, функциями и т.д.).

Таким образом, полученные результаты используются не так точно, как хотелось бы, но тем не менее, как нам кажется, выявляют общую тенденцию. В следующей таблице приведены основные вопросы и ответы. Они рассчитываются в соответствии с количеством ответов, степенью согласия по пятибалльной шкале или их максимальным цитированием в $\mathrm{n} 1$.

\section{- Обработка ответов}

Принимая во внимание все ответы, даже самые раз-

\begin{tabular}{|c|c|c|c|c|}
\hline Заданные вопросы & Ответы 1 & $\begin{array}{c}\text { соотношение ответа } \\
\text { или позиция }\end{array}$ & Ответы 1 & $\begin{array}{c}\text { соотношение ответа } \\
\text { или позиция }\end{array}$ \\
\hline $\begin{array}{l}\text { Причины вашей работы в банков- } \\
\text { ском деле }\end{array}$ & $\begin{array}{l}\text { Потому что вы ищете стабиль- } \\
\text { ную работу с возможностью } \\
\text { карьерного роста в секторе, } \\
\text { сочетающем различные про- } \\
\text { фессии. }\end{array}$ & $65 \%$ & $\begin{array}{l}\text { Потому что вам приходилось } \\
\text { работать, чтобы зарабатывать на } \\
\text { жизнь, и появилась возмож- } \\
\text { ность }\end{array}$ & $35 \%$ \\
\hline Причины выбора этого банка & $\begin{array}{l}\text { Независимо от банка, вы вы- } \\
\text { брали наиболее выгодное для } \\
\text { вас предложение }\end{array}$ & $50 \%$ & $\begin{array}{l}\text { Для уровня renumiration и другие } \\
\text { преимущества }\end{array}$ & $46 \%$ \\
\hline $\begin{array}{l}\text { Опишите свою профессиональную } \\
\text { деятельность как: }\end{array}$ & $\begin{array}{l}\text { Деятельность, связанная с } \\
\text { вашей профессией }\end{array}$ & $46 \%$ & $\begin{array}{l}\text { Деятельность банковского } \\
\text { агентства в целом }\end{array}$ & $31 \%$ \\
\hline $\begin{array}{l}\text { Элементы, оказывающие наиболь- } \\
\text { шее влияние на построение вашей } \\
\text { идентичности }\end{array}$ & $\begin{array}{l}\text { Ваши навыки и предыдущий } \\
\text { опыт работы в этом банке. }\end{array}$ & 13 позиция $\mathrm{n}^{\circ} 1$ & Мой опыт в этом банке & 6 позиция $\mathrm{n}^{\circ} 2$ \\
\hline $\begin{array}{l}\text { Степень согласия с моим предложе- } \\
\text { нием относительно присвоения его } \\
\text { профессии? }\end{array}$ & $\begin{array}{l}\text { В моей профессии есть свои } \\
\text { правила, я не могу от них от- } \\
\text { клоняться. }\end{array}$ & $\begin{array}{c}\text { Степень согласия: } \\
3.8 / 5\end{array}$ & $\begin{array}{l}\text { Мои навыки и мой опыт имеют } \\
\text { значение }\end{array}$ & $\begin{array}{l}\text { Степень согласия: } \\
3.6 / 5\end{array}$ \\
\hline $\begin{array}{l}\text { Степень согласия с предложениями: } \\
\text { предмет управления персоналом }\end{array}$ & Я только часть компании & $\begin{array}{c}\text { Степень согласия: } \\
3.8 / 5\end{array}$ & $\begin{array}{l}\text { Я буду признателен за большее } \\
\text { индивидуальное признание }\end{array}$ & $\begin{array}{l}\text { Степень согласия: } \\
2.8 / 5\end{array}$ \\
\hline Вы работаете на: & $\begin{array}{l}\text { Вознаграждение на первичные } \\
\text { нужды }\end{array}$ & 23 позиция $\mathrm{n}^{\circ} 1$ & Взорвано ответы & \\
\hline $\begin{array}{l}\text { Какие из предложенных тем позво- } \\
\text { ляют вам определить себя? }\end{array}$ & Твоя семья & $92 \%$ & $\begin{array}{l}\text { Ваша работа, ваша профессио- } \\
\text { нальная ситуация, учеба. }\end{array}$ & $85 \%$ \\
\hline
\end{tabular}


розненные по количеству ответов, мы смогли выделить 5 основных тем: причина выбора банка, векторы идентичности, присвоение профессии, удовлетворенность сотрудников и место работы в самоопределении.

- От профессионального проекта до интеграции в банк

Подавляющее большинство сотрудников ответили, что именно различные преимущества карьеры в банковском секторе привели их к работе в финансовом учреждении. Действительно, их ответы отражают реальный энтузиазм по поводу стабильности работы, относительно характерный для банковского сектора. Они также указывают на то, что возможности карьерного роста и разнообразие профессий оказали очень большое влияние на выбор ими профессиональной деятельности. Некоторые добавляют, что важность человеческих контактов в повседневной банковской деятельности утешила их в их решении присоединиться к этой сфере. С другой стороны, связь между идентичностью самого банка или его культурой и их личностью не доказана. Таким образом, первый вывод нашего исследования состоит в том, что изначально выбор банковского сектора связан не с реальной привлекательностью для мира финансов, а, скорее, с мотивацией качества жизни, которое этот сектор может обеспечить с точки зрения стабильность и карьерный рост.

\section{- Векторы идентичности}

Сначала мы хотели узнать, с чем идентифицируют сотрудников этого банка: со своим бизнесом, группами, компанией или сектором деятельности. Профессия - важнейший вектор идентичности. 50\% опрошенных ответили, что описали бы деятельность, связанную с их функцией, чтобы описать свою профессиональную деятельность. Этот результат демонстрирует индивидуальный характер профессиональной идентичности. Чуть более $30 \%$ респондентов описали бы свою профессиональную деятельность через деятельность банковского агентства в целом. Эти ответы отражают относительно сильную идентификацию с группой. Наконец, 20\% респондентов описали бы деятельность и функционирование этого банка, чтобы определить свою профессиональную деятельность. Таким образом, компания действительно может рассматриваться как вектор идентичности, в то время как сектор, похоже, не оказывает прямого влияния на идентичность респондентов.

Так же мы хотели определить основные векторы идентичности в этом банке для физических лиц: навыки и предыдущий опыт являются основным вектором профессиональной идентичности для наших респондентов. Таким образом, образование, будь то семья или школа, служит основой для построения идентичности. Затем следует классификация, практика использования профессии и опыт, полученный в компании. Эти три элемен- та имеют общие индивидуальные характеристики. Таким образом, как упоминалось выше, именно личный и индивидуальный опыт сотрудников в банковском секторе является наиболее творческой составляющей идентичности. Тогда именно элементы, относящиеся к группам, рассматриваются как второй вектор идентичности. Действительно, именно отношения с остальным персоналом и передача опыта были названы в честь первой группы элементов, изученных ранее. Это замечание подчеркивает важность «другого» в процессе построения идентичности. Здесь идентичность приобретает коллективный характер.

\section{- Присвоение профессии}

Как и следовало ожидать, сотрудники осознают, что банковское дело - это отрасль, которая строго регулируется и контролируется. Они ясно указывают на то, что у них мало места для маневра перед лицом этой реальности. Сотрудники признают, что они не могут персонализировать свою работу или использовать свои собственные стратегии и логику действий. На самом деле у них есть только несколько возможностей действия, пробуждения или воображения. Таким образом, банковский сектор не представляется идеальной основой для присвоения и персонализации профессиональных действий. Сотрудники каким-то образом связаны рамками, которые они не могут переопределить. Они должны следовать процедуре без малейшей возможности ее обойти. Их единственной альтернативой самореализации остаются их навыки, знания и личный опыт. Эти три элемента составляют их силу, позволяющую отличаться от своих сверстников.

\section{- Удовлетворенность сотрудников}

Эта часть исследования показывает, что у соответствующего банка есть некоторая удовлетворенность управлением. Действительно, с точки зрения респондентов, навыки и знания сотрудников кажутся относительно признанными обществом. Однако результаты обычно отражают отсутствие индивидуального признания. Большинство респондентов считают, что компания рассматривает их только как число: если сотрудники с эквивалентной функцией выполняют одинаковую деятельность и все они выполняют свои функции, соблюдая одни и те же правила и одни и те же цели, тогда все они взаимозаменяемы. Кроме того, компания не уделяет должного внимания личным требованиям сотрудников. И если компания действительно пытается внедрить индивидуализированное управление персоналом, она вынуждена идти через посредников, которые представляют собой различные подразделения национального, регионального и ведомственного управления человеческими ресурсами.

- Место работы в самоопределении

Когда мы попросили х человек выбрать три элемен- 
та, которые позволили бы определить их и сказать, что они собой представляют, 85\% респондентов процитировали работу, рассматриваемую здесь в целом (то есть как работу, так и профессиональную ситуацию и исследования). Семья остается самым популярным элементом в ответах наших сотрудников: 92\% сотрудников ссылаются на нее среди трех выбранных критериев. Третий по популярности предмет - «друзья». В этих двух элементах мы находим понятие коллективности в определении себя. Эта тенденция может отражать потребности других, а также привязанность к отношениям, которые нам удалось создать и поддерживать. Человек осознает, что он ничто без других. Таким образом, он выбирает эти элементы более инстинктивно, чем те, которые связаны с личными характеристиками; или: его увлечения, места, к которым он привязан, его географическое происхождение, его политические или религиозные взгляды или его внешний вид. Таким образом, работа действительно занимает преобладающее место в определении личности сотрудников в банковском секторе. Если это только второй фактор, который чаще всего упоминается нашими респондентами, он, тем не менее, свидетельствует о сильной идентичности на работе.

\section{- Обсуждение}

Эти результаты показывают, что большинство сотрудников не нашли себе работу по своей профессии. Более того, они считают, что адаптировали свою личность и личность к той профессиональной среде, которую они интегрировали. Только 19\% опрошенных сотрудников нашли работу в банковском секторе, которая им подходила. При обработке ответов мы наблюдаем большую корреляцию между исходными причинами выбора профессиональной среды и адаптацией идентичности к трудовой деятельности. У каждой компании свой стиль, связанный с личностью ее менеджеров и сотрудников, а также с ее культурой и сектором деятельности. Таким образом, потратив время на поиск наименьшего общего знаменателя между своей идентичностью и идентичностью компании, индивид создает профессиональную идентичность, которая похожа на него. Поскольку профессиональная идентичность строится на основе образования, в данном случае она принимает направление, аналогичное исходной глобальной идентичности человека. Однако оказывается, что сотрудники для многих выбрали этот банк из-за качества жизни, которое он пытается принести своим сотрудникам, а не из-за имиджа, который он создает, или из-за существующей согласованности между ними. и идентичность в целом.

Затем мы можем пролить свет на взаимное влияние, которое существует между профессиональной идентичностью сотрудников и идентичностью компании. Для этого мы можем выделить две оси: «Как компания влияет на профессиональную идентичность своих сотрудников?»; но также: «Почему компания заинтересована в продвижении идентичности своих сотрудников?»

Хотя компания теоретически является вектором идентичности, мы заметили, что она мало влияет на формирование идентичности сотрудников в банковском секторе. Именно индивидуальный опыт и навыки в сочетании с групповой социализацией в основном способствуют формированию идентичности сотрудников. Таким образом, в изучаемом контексте компания имеет лишь ограниченное влияние на процесс создания идентичности. Ранее мы разъясняли во введении основные проблемы для компании, связанные с успехом построения идентичности ее сотрудников. Напомним ключевую идею: профессиональная идентичность напрямую связана с удовлетворенностью и благополучием сотрудников, а также с качеством жизни на работе. Проведенный нами полевой анализ привел нас к различным наблюдениям на предмет и расхождения между потребностями компаний и потребностями сотрудников. Сотрудники сожалеют об отсутствии индивидуального подхода к делу, хотя банк, похоже, делает все, чтобы адаптировать индивидуальное управление своим персоналом. Кроме того, рабочие сталкиваются с невозможностью адаптировать свои профессиональные действия к своей личности и своему воображению. К сожалению, это наблюдение может быть усилено в будущем, учитывая различные события, ставшие недавними новостями в банковском секторе. В этом контексте внутренний контроль уже начал расширяться. Можно представить, что они и дальше будут укрепляться. Таким образом, безопасность будет препятствием для персонализации профессии в банковском секторе. Таким образом, наша работа оставляет перспективы для дальнейших исследований и возможности углубления определенных осей. В частности, можно было бы поработать над ролью менеджера в процессе формирования идентичности, а также над влиянием ценностей компании и их влиянием на профессиональную идентичность.

\section{Выво}

Эти результаты позволяют нам сделать вывод, что стремление к принадлежности и признанию в организациях, несомненно, представляет собой фундаментальное измерение профессиональной идентичности человека и важный параметр для оценки качества жизни на работе. Случай с банком, изученный в этой структуре, вероятно, подтвердит этот тезис.

Но если ключи к расшифровке профессиональной идентичности связаны с качеством жизни на работе, возникает следующий вопрос: как рассматривать пребывание в организации, в которой отсутствует ее собственная конструкция? Эти элементы действительно будут все больше и больше оцениваться будущими сотрудниками в форме самоанализа: почему бы мне работать в вашей 
компании, а не в другой?

Ответ лежит как в организации, так и в индивидуальном и во взаимодействии между индивидуумом и бизнесом. В экономическом контексте, основанном на поиске конкурентоспособности, инвестирование в благополучие является мощным рычагом с точки зрения предотвращения несчастных случаев, мотивации на работе, чувства принадлежности и удержания руки. -работай. Сотрудники довольны собой: это не роскошь, а конку- рентное преимущество. В организации работы на мотивацию в первую очередь влияет чувство эффективности: смысл работы заключается в отношениях, которые человек устанавливает между тем, что он делает на работе, и что это позволяет ей сказать о себе. Профессиональная идентичность, ее построение и то, как она воспринимается в организации, способствует этой эффективности, а еще лучше - чувству полезности как человека. И если это не существенное измерение, это хотя бы элемент построения человека на своем рабочем месте.

ЛИТЕРАТУРА

1. Альберт Э., Бурнуа Ф., Дюваль-Хамель Дж., Рожо Дж., Руссильон С., Сэнсаулье Р. (2003), Почему я пойду на работу, Eyrolles.

2. Дубар К. (2000), Кризис идентичностей, Интерпретация мутации, Париж. PUF.

3. Дубар К. (2000), Социализация. Построение социальной и профессиональной идентичности, Арманд Колин, сборник U (3-е изд.).

4. Франкфурт И., Ости Ф., Саинсаулиё Р., Ухальде М. (1995) Социальные миры компании, Desclée de Brouwer.

5. Гарнье Х., Мед а Д., Сеник К., (2006), Место работы в личности, Экономика и статистика - Insee - 393-394.

6. Гоффман Э. (1973), Представление самого себя, Éditions de Minuit, cб. Le Sens Commun, Париж.

7. Гойер К., Алин К. (2000), Преподаватель-форматер: построение профессиональной идентичности, L'Harmattan, Collection Education и др.

8. Оноре Л., (2002), Трансформация трудовых отношений, разрыв профессиональной идентичности и дисциплинарной динамики, Управление человеческими ресурсами, № 43.

9. Hugues EC, (1996), Le Relations sociologique, EHESS.

10. Ости Ф., (2008), Стремление к работе - приверженность, идентичность и признание в работе, Rennes University Press, Koллекция «des Sociétés».

11. Picouleau S., (2009), Профессиональная идентичность: пример построения идентичности в банковском секторе, магистерская работа, под руководством AM. Fray, ESCEM, Tours.

12. Руссо Ж.Дж., (1755,) Рассуждение о происхождении и основаниях неравенства между мужчинами, Фолио, 1989, Париж.

13. Сартр Дж.П., (1946), Экзистенциализм - это гуманизм, Издание Gallimard, 1996 г. в коллекции Folio.

14. Sainsaulieu P., (1985), Идентичность на работе - эффекты культуры в организации - Нажмите National Science Foundation политики.

15. Winnicot DW., (1975), Игра и реальность, потенциальное пространство, Essais Folio, Париж. 